\title{
Biodegradable Calcium Phosphate Nanoparticle with Lipid Coating for Systemic siRNA Delivery
}

\author{
Jun Li, Yun-Ching Chen, Yu-Cheng Tseng, and Leaf Huang ${ }^{\star}$ \\ Division of Molecular Pharmaceutics, Eshelman School of Pharmacy, University of North Carolina \\ at Chapel Hill, Chapel Hill, NC 27599, USA
}

\begin{abstract}
A lipid coated calcium phosphate (LCP) nanoparticle (NP) formulation was developed for efficient delivery of small interfering RNA (siRNA) to a xenograft tumor model by intravenous administration. Based on the previous formulation, liposome-polycation-DNA (LPD), which was DNA-protamine complex wrapped by cationic liposome followed by post-insertion of PEG, LCP was similar to LPD NP except that the core was replaced by a biodegradable nano-sized calciumphosphate precipitate prepared by using water-in-oil micro-emulsions in which siRNA was entrapped. We hypothesized that after entering the cells, LCP would de-assemble at low $\mathrm{pH}$ in the endosome, which would cause endosome swelling and bursting to release the entrapped siRNA. Such a mechanism was demonstrated by the increase of intracellular $\mathrm{Ca}^{2+}$ concentration as shown by using a calcium specific dye Fura-2. The LCP NP was further modified by post-insertion of polyethylene glycol (PEG) with or without anisamide, a sigma-1 receptor ligand for systemic administration. Luciferase siRNA was used to evaluate the gene silencing effect in H-460 cells which were stably transduced with a luciferase gene. The anisamide modified LCP NP silenced about $70 \%$ and $50 \%$ of luciferase activity for the tumor cells in culture and those grown in a xenograft model, respectively. The un-targeted NP showed a very low silencing effect. The new formulation improved the in vitro silencing effect 3-4 folds compared to the previous LPD formulation, but had a negligible immunotoxicity.
\end{abstract}

\section{Keywords}

Calcium phosphate; Nanoparticle; Cancer; PEGylation; siRNA

\section{Introduction}

Non-viral vector for the delivery of nucleic acid has been studied since the 1990s. We have designed a modular method to assemble a core/shell NP structure which was named LPD [14]. The negatively charged DNA-protamine core allows subsequent wrapping by cationic liposomes. The resulting positively charged NP were further modified by inserting doublechain phospholipid conjugate of polyethylene glycol (PEG) to impart a steric barrier for prolonged circulation time in the blood. The distal end of PEG is tethered with a small targeting ligand such as anisamide for rapid and specific internalization of the bound NP [5]. Although

(C) 2009 Elsevier B.V. All rights reserved.

*Corresponding author. leafh@email.unc.edu.

Publisher's Disclaimer: This is a PDF file of an unedited manuscript that has been accepted for publication. As a service to our customers we are providing this early version of the manuscript. The manuscript will undergo copyediting, typesetting, and review of the resulting proof before it is published in its final citable form. Please note that during the production process errors may be discovered which could affect the content, and all legal disclaimers that apply to the journal pertain. 
LPD showed a striking success in delivering siRNA after intravenous injection, the release of siRNA into the cytoplasm is variable depending on the cells and still has room for improvement. Large molecular weight carbohydrate, hyaluronic acid, has been used to replace the DNA in LPD formulation which caused immunotoxicity [6].

Calcium phosphate $(\mathrm{CaP})$ is a well used non-viral vector for in vitro transfection of a wide variety of mammalian cells with little toxicity[7]. The delivery activity is probably related to the fact that $\mathrm{CaP}$ rapidly dissolves in the acidic $\mathrm{pH}$ [8] Endocytosed $\mathrm{CaP}$ is expected to deassemble in the endosomes and release its cargo into the cytoplasm. Many investigators, including ourselves, have attempted to improve the manufacture of the CaP precipitate with limited success [9]. Many other approaches have been attempted to prepare nano-sized $\mathrm{CaP}$ particles to improve the transfection reproducibility and efficiency. For example, Maitra and colleagues condensed DNA in a reverse micro-emulsion environment to prepare CaP NPs of $100-120 \mathrm{~nm}$ in diameter $[8,10,11]$. The colloids aggregate rapidly with time and only in vitro transfection has been reported. Epple et al. developed a formulation of CaP NPs by rapid precipitation followed by immediate adsorption of DNA or siRNA, which also stabilized the CaP colloids [12-14]. The stabilized NPs showed 100-200 nm in size and could transfect cells with a GFP plasmid or silenced the expression of GFP in the treated cells. Liu et al. reported a preparation of 24-35 nm CaP NPs coated with bovine serum albumin as a DNA vector in vitro [15]. However, the formulation was not tested via systemic administration. Thus, it would be a great improvement if one could combine the advantage of LPD and CaP NP to achieve a prolonged circulation time and an elevated endosome release mechanism.

Thus, we have replaced the core of LPD NP with the acid-sensitive CaP. The resulting new formulation is called Liposome/Calcium/Phosphate, or LCP. The CaP core should dissolve in the endosomes, causing osmotic swelling to release the encapsulated siRNA. After further modification of a targeting ligand with a PEG linker, the LCP NP showed excellent siRNA delivery activity in cultured tumor cells and in a xenograft tumor model.

\section{Materials and Methods}

\subsection{Materials}

1 ,2-dioleoyl-3-trimethylammonium-propane chloride salt (DOTAP), cholesterol, 1,2distearoryl-sn-glycero-3-phosphoethanolamine- $\mathrm{N}$-[methoxy(polyethyleneglycol-2000) ammonium salt (DSPE-PEG) were purchased from Avanti Polar Lipids, Inc. (Alabaster, AL). DSPE-PEG-anisamide was synthesized in our lab as described elsewhere [16]. Fura-2 AM was purchased from Invitrogen Inc. (Carlsbad, CA) and dissolved in DMSO to prepare $1 \mathrm{mM}$ store solution. Anti-luciferase siRNA (target sequence 5'-CTT ACG CTG AGT ACT TCG A-3') was purchased from Dharmacon (Lafayette, $\mathrm{CO}$ ) in deprotected, desalted, annealed form. Other chemicals were obtained from Sigma-Aldrich (St. Louis, MO) without further purification.

NCI-H-460 cells (human lung cancer cells) were obtained from American Type Culture Collection and were stably transduced with GL3 firefly luciferase gene using a retroviral vector produced in Dr. Pilar Blancafort's lab at the University of North Carolina at Chapel Hill. The cells were maintained in RPMI 1640 cell culture medium with $10 \%$ fetal bovine serum (Invitrogen, Carlsbad, CA), $100 \mathrm{U} / \mathrm{ml}$ penicillin, and $100 \mu \mathrm{g} / \mathrm{ml}$ streptomycin (Invitrogen, Carlsbad, CA). H460 cells were previously shown to be sigma-1 receptor positive [1].

\subsection{Experimental animals}

Female athymic nude mice of age 6-8 weeks were purchased from Charles River Laboratories (Wilmington, MA). All work performed on animals were in accordance with and approved by the University of North Carolina Institutional Animal Care and Use Committee. 


\subsection{The preparation of LCP}

Fig. 1 shows a diagram for the preparation of the lipid coated calcium phosphate (LCP) NP. Briefly, $250 \mathrm{mM} \mathrm{CaCl}_{2}$ and $250 \mathrm{mM} \mathrm{NaHPO}_{4}$ solutions were prepared in aqueous solution and both of the $\mathrm{pH}$ values were adjusted by $1 \mathrm{M}$ ammonium to $\mathrm{pH} 9$. One hundred and fifty $\mu \mathrm{l}$ of $\mathrm{CaCl}_{2} 100 \mu \mathrm{l}$ of $\mathrm{NaHPO}_{4}$ with $25 \mu \mathrm{l}$ anti-luciferase siRNA $(2 \mathrm{mg} / \mathrm{ml})$ were dispersed in 7 $\mathrm{ml}$ cyclohexane/Triton-X100/hexanol to form a reverse water-in-oil micro-emulsion, respectively. After mixing the above two solution for $15 \mathrm{~min}, 125 \mu 1$ of $15 \mathrm{mM}$ sodium citrate was added dropwise to the micro-emulsion and the solution continued to be transparent. With the incubation for another $15 \mathrm{~min}, 1 \mathrm{~g}$ silica gel (60-200 mesh) was added to absorb the formed calcium phosphate nano-precipitate with the entrapped siRNA. The silica gel was washed by ethanol and eluting with ethanol/water (3/1, volume ratio). The calcium phosphate core with siRNA could be stored in elution solution for at least one week.

The obtained NP core was dispersed in water after removing ethanol by rotary evaporation and mixed with 1:1 molar ratio of DOTAP-cholesterol (10 mM total lipid) liposome extruded by a $100 \mathrm{~nm}$ membrane for more than 15 times to form the unmodified LCP. The amount of DOTAP was optimized by detecting the Z-potential of LCP in $1 \mathrm{mM} \mathrm{KCl}$ by a Zeta Plus potential analyzer (Brookhaven Instrument Corporation, Holtsville, NY) and the size of the unmodified LCP was determined by a submicron particle sizer (NICOMP particle sizing system, AutodilutePAT Model 370, Santa Barbra, CA).

To qualitatively calculate the trapping efficiency of siRNA in LCP nanoparticle, the antiluciferase siRNA was replaced by the same sequence siRNA with FAM labeling (Dharmacon Inc, Lafayette, CO). The FAM-labeled siRNA entrapped LCP nano-particles were dissolved in the same amount of lysis buffer ( $2 \mathrm{mM}$ EDTA and $0.05 \%$ Trixton- 100 in pH 7.8 Tris buffer) for quantitative analysis of the siRNA encapsulation efficiency. The standard siRNA solutions were prepared by diluting the original FAM-labeled siRNA in the same lysis buffer. Then, 100 $\mu 1$ of each standard and LCP solution was taken to the 96-well plate and the fluorescence intensity was measured on plate reader (Plate Chameleon Multilabel Detection Platform, Bioscan Inc., Washington DC) to record the fluorescence intensity at $525 \mathrm{~nm}$. The amount of entrapped siRNA was calculated according to the standard calibration curve.

Transmission electron microscope (TEM) images of the CaP core and resulting LCP were acquired by the use of JEOL 100CX II TEM (JEOL, Japan). Briefly, $5 \mu$ l of CaP NP was dropped on to a 300 mesh carbon coated copper grid (Ted Pella, Inc., Redding, CA). For LCP, $1 \%$ uranyl acetate was used to stain the NP for 5 min before the observation with TEM.

Untargeted LCP and targeted LCP were prepared by incubating $330 \mu 1$ unmodified LCP (10 $\mathrm{mM}$ lipid) with $37.8 \mu 1$ DSPE-PEG2000 or DSPE-PEG-anisamide $(10 \mathrm{mg} / \mathrm{ml})$ at $50^{\circ} \mathrm{C}$ for 10 $\mathrm{min}$, respectively, and then allowed to stand at room temperature for $10 \mathrm{~min}$ before use.

Liposome-protamine-DNA (LPD) NP was prepared as previously described [17].

\subsection{Calcium release in live cells by LCP}

Two $\mu 1$ of $2 \mathrm{mM}$ Fura- $2 \mathrm{AM}$ and $2 \mu \mathrm{l}$ of $20 \%$ Pluronic- 127 were mixed for $5 \mathrm{~min}$ and freshly prepared in $1 \mathrm{ml}$ phenol red free DMEM cell culture medium before usage. About $5 \times 10^{4} \mathrm{H}-460$ cell was incubated in Lab-Tek 8 well Glass Chamber Slide System (Fisher, Pittsburgh, PA) for $24 \mathrm{~h}$. Two hundred $\mu \mathrm{l}$ of $2 \mu \mathrm{M}$ Fura-2 AM solution was added to the cell culture chamber and incubated for $50 \mathrm{~min}$. After washing by PBS twice, the cells were incubated in phenol red free DMEM cell culture medium and imaged in Nikon TE2000U microscope with OrcaER Camera. The emission was monitored at $510 \mathrm{~nm}$ with the alternate excitation wavelength of $340 \mathrm{~nm}$ and $380 \mathrm{~nm}$ from a Xenon light source. After adding $50 \mu \mathrm{l} \mathrm{LCP}$, the fluorescence image was obtained by setting excitation at $340 \mathrm{~nm}$ for green color and $380 \mathrm{~nm}$ for red color. The 
ratio of $340 \mathrm{~nm} / 380 \mathrm{~nm}$ was proportional to the intracellular free $\mathrm{Ca}^{2+}$ concentration [18]. All experiments were performed at room temperature.

For the inhibition of endocytosis, $20 \mathrm{mM}$ cytochalasin $\mathrm{D}$ was prepared in DMSO solution and freshly diluted 1,000 times by phenol red free DMEM medium for usage. After incubated with Fura- $2 \mathrm{AM}$ for $60 \mathrm{~min}$ and $20 \mu \mathrm{M}$ cytochalasin $\mathrm{D}$ for $5 \mathrm{~min}$, the cells were imaged as described with the addition of LCP.

\subsection{In vitro luciferase gene silencing study}

H-460 cells with stable luciferase expression were seeded in 96 well plates. After reaching $60 \%$ confluency, the cells were treated with different formulations of LCP containing antiluciferase siRNA in the culture medium at $37^{\circ} \mathrm{C}$ for $24 \mathrm{~h}$. All of the siRNA was FAM labeled and calibrated according to the method described in Materials and Methods 2.3. Cells were washed with PBS twice followed by incubation with $100 \mu \mathrm{l}$ lysis buffer at $4^{\circ} \mathrm{C}$ for $1 \mathrm{~h}$. Twenty $\mu 1$ lysate was mixed with $80 \mu 1$ substrate (Luciferase Assay System, Promega Co., Madison, WI) and the luminescence intensity was measured by the plate reader (Bioscan Inc., Washington DC). The total protein concentration in the lysate was determined by using a protein assay kit (Micro BCA ${ }^{\mathrm{TM}}$ Protein Assay Kit, Pierce). The activity of luciferase is shown as the luminescence intensity per $\mu \mathrm{g}$ protein.

Data are presented as the mean $\pm \mathrm{SD}$. The statistical significance was determined by using the analysis of two-sided student t-test. P values of $<0.05$ were considered to be significant.

\subsection{In vivo luciferase gene silencing study}

H-460 cells $\left(2 \times 10^{5}\right)$ with luciferase expression were subcutaneously injected into the lower back of female nude mice (about $20 \mathrm{~g}$ ), and allowed to grow to tumor size of about 400 $\mathrm{mm}^{3}$. The mice were randomly assigned to different treatment groups ( $\mathrm{n}=3$ for each group). Mice were tail-vein injected with LCP-PEG or LCP-PEG-AA containing $24 \mu \mathrm{g}$ anti-luciferase siRNA or the controlled siRNA, which sequence is 5'-AAT TCT CCG AAC GTG TCA CGT-3' [17]. Similar LPD formulations containing the identical amounts of anti-luciferase or control siRNA were also prepared and used for comparison. After $24 \mathrm{~h}$, the tumors were harvested, weighted and homogenized in lysis buffer with a volume of lysis buffer (ml)/ tumor weight $(\mathrm{g})$ ratio of 2 . The following steps were the same as the in vitro study.

\subsection{Immunotoxicity Assay}

C57BL/6 mice were i.v. injected with targeted LCP and LPD nanoparticle with the entrapped anti-luciferase siRNA at $0.6 \mathrm{mg} / \mathrm{kg}$ and $1.2 \mathrm{mg} / \mathrm{kg}$. After $4 \mathrm{~h}$ of the injection, blood samples were collected from the tail artery and allowed to stand at room temperature for $0.5 \mathrm{~h}$ for coagulation. Serum was obtained by centrifuging the clotted blood at 13,000 rpm for $20 \mathrm{~min}$. Cytokine levels were determined by using ELISA kits for IL6 and IL12 (BD Biosciences, San Diego, CA)

\section{Results and Discussion}

\subsection{The hypothesis of siRNA release from LCP NP in the endosome}

One of the key steps in the NP-mediated intracellular delivery of macromolecules, including siRNA is the release of the cargo from the endosomes. This subject has been recently reviewed by us [19]. Several mechanisms have been explored to explain how DNA/polymer complex, i.e., polyplex, could escape from the endosome. The well accepted proton sponge effect [20] is probably not the major mechanism of endosome escape of the polyplex, because free cationic polymer is required for activity [21]. Ion-pair formation between the cationic groups of the polymer and anionic lipids in the endosome membrane is more likely the mechanism [22]. 
However, it is also necessary to coat the NP with a PEG layer to prolong the circulation time and enhance the tumor uptake via the enhanced permeability and retention (EPR) effect [23]. PEG layer on the surface of the NP effectively shields the positive charges such that no significant ion pairs can be formed with the endosome lipids. This is probably why much of the internalized siRNA in the LPD NP is still sequestered in the endosomes [2]. Thus, the release mechanism for nucleic acid from the PEGylated NP into the cytoplasm could still be significantly improved.

As the oldest non-viral gene vector, calcium phosphate $(\mathrm{CaP})$ composites could encapsulate nucleic acid due to the high affinity of $\mathrm{Ca}$ ion to the phosphate groups in the nucleic acids $[24,25]$. After being taken up by the cell, the composite is dissolved in the acidic environment of the endosome and releases the encapsulated nucleic acid into the cytoplasm. Therefore, the release of nucleic acid is not related to the ion-pair formation and has the potential to improve the release of nucleic acid from PEGylated NP from the endosome. The hypothesis of the release is shown in Figure 2.

As shown in the Figure 2, there are several steps for siRNA released from LCP. (1) The LCP enters the cell through the endocytosis and stays in the endosome. (2) The CaP core is dissolved at low pH, causing NP de-assembly. (3) The dissolved calcium and phosphate ions increase the osmotic pressure and cause endosome swelling. (4) The endosome bursts and release the siRNA, calcium and phosphate ions into the cytoplasm.

Since we do not change the shell of the NP, PEGylated and ligand targeted LCP is expected to accumulate in the tumor by the EPR effect, just like LPD [17].

\subsection{The characteristics of LCP NP}

To encapsulate siRNA in nano-scale particles, the nucleic acid should be confined in a nanosized space when the particles are assembled. We have used a reverse water-in-oil microemulsion to entrap siRNA by calcium phosphate precipitate in a nano-sized reactor.

Furthermore, the particles should contain a negatively charged surface for coating with positively charged liposome[26]. This was done by adding $125 \mu 1$ of $15 \mathrm{mM}$ sodium citrate to the micro-emulsion [27]. The organic solvent and surfactant were removed by immobilizing the CaP NP in silica gel and extensively washed by EtOH and water. The resulting spherically shaped CaP NP (Figure 3A) was fairly homogenous with an average diameter of about 60-80 $\mathrm{nm}$. Addition of EtOH or acetone to the micro-emulsion followed by centrifugation was also attempted to separate the NP from the surfactants. Large sized precipitate was always obtained due to the aggregate of the NP (data not shown). The addition of citrate also played a critical role to stabilize the formed CaP NP because citrate was absorbed on the surface of NP to have a negative charge. In this process, $15 \mathrm{mM}$ citrate was chosen to endow the CaP NP with a zeta potential about -14 to $-20 \mathrm{mV}$. Thus, the resulting CaP NP could serve as the cores for the formation of LCP.

The particle size and zeta potential of the LCP depended on the ratio of DOTAP/cholesterol liposome to CaP NP. As shown in Figure $3 \mathrm{C}$, the $\mathrm{CaP}$ NP in this representative experiment was about $80 \mathrm{~nm}$ in size with a zeta potential about $-16 \mathrm{mV}$. The addition of DOTAP/cholesterol liposome caused an increase in the zeta potential of the complex until a neutrally charged yet very large aggregate $(900 \mathrm{~nm})$ formed at the ratio of 417 since the net charge of positive charged liposome and negative charged calcium phosphate core are equal. With the continuous addition of DOTAP/cholesterol liposome, the complex showing a positive charge and stable colloids with a size of approximately $150 \mathrm{~nm}$ were obtained. The surface charge continuously increased to $+38 \mathrm{mV}$ with a stable size of $150 \mathrm{~nm}$ until the ratio reached 834 . To assure the CaP NP was fully covered by the liposome, a slight excess lipid was used at the ratio of 973 and the final particles showed a zeta potential of about $+40 \mathrm{mV}$ and an average diameter of $150 \mathrm{~nm}$. With 
the negative staining, the TEM imaging showed a coated layer on the calcium phosphate core (Figure 3B), i.e. LCP NP was obtained. Using a fluorescence labeled siRNA, the final encapsulation efficiency of siRNA in LCP was measured to be $39.8 \pm 2.8 \%(\mathrm{n}=3)$.

It is difficult to avoid empty liposomes if excess liposomes were added to the calcium phosphate cores. However, the amount of cationic liposomes has been carefully titrated such that the total positive charge in added cationic liposomes was roughly the same as the total negative charges on the cores. Under such condition, there should be no excess empty liposomes in the final preparation.

\subsection{Imaging of intracellular calcium release from LCP NP}

It is well known that the $\mathrm{CaP}$ precipitate rapidly dissolves at an acidic $\mathrm{pH}$ and releases calcium ions. Protons should be able to penetrate the lipid membrane of LCP to dissolve the CaP core. The colloid CaP and LCP showed a light scattering absorbance at $275 \mathrm{~nm}$ and $270 \mathrm{~nm}$, respectively. We have tested the dynamic change of light scattering at different $\mathrm{pH}$ as shown in Figure 4A. At neutral $\mathrm{pH} 7.0$, both $\mathrm{CaP}$ and $\mathrm{LCP}$ remained unchanged during the period of time tested, i.e., $10 \mathrm{~min}$. When the $\mathrm{pH}$ was dropped to $6.0,30 \%$ of the CaP NP disappeared after 10 min, but the LCP NP did not change too much. With continuous drop of $\mathrm{pH}$, the light scattering of LCP NP decreased $60 \%$ in 10 min, showing a significant acid-sensitive characteristic. It is well known that the $\mathrm{pH}$ value in the endosome of tumor cells can be as low as 5.0. Thus, the LCP NP should de-assemble at this $\mathrm{pH}$ and release its cargo, i.e., siRNA. This observation was in accordance with the hypothesis shown in Figure 2.

Fura-2-acetoxymethyl ester (Fura-2 AM), is a membrane permeable derivative of Fura-2 to measure cellular calcium concentrations by fluorescence imaging. After entering the cell membrane, Fura-2 AM is converted to Fura-2 by cellular esterase. Fura-2 binds with intracellular free calcium and blue-shifts its emission [18]. The ratio of the emissions at 340 $\mathrm{nm}$ and $380 \mathrm{~nm}$ is directly correlated to the amount of intracellular calcium [28]. After loading with $2 \mu \mathrm{M}$ Fura-2 AM, the tumor cells were incubated with the unmodified LCP and imaged by confocal microscopy as shown in Figure 4B. A significant color change was observed in the cells after the addition of LCP. White arrows indicate representative cells changing color from orange/red (low calcium) to green (high calcium) although not all of the cells changed their color. Since unmodified LCP is positively charged, we checked to see if the color change of cells was the result of interacting with cationic particles. DOTAP/cholesterol liposome $(+40$ $\mathrm{mV}$ in zeta potential) was added to Fura-2 labeled cells. The liposome did not cause any color change, thus ruling out the possibility (data not shown). To verify that the color change really came from the release of calcium in LCP, an endocytosis inhibitor, cytochalasin D, was used to inhibit the endocytosis of LCP in the tumor cells. The addition of cytochalasin D significantly reduced the change of color from orange/red to green, showing the uptake of LCP NP was endocytosis dependent (data not shown). These results strongly support the hypothesis described in Figure 2.

\subsection{In vitro luciferase gene silencing effect of LCP}

The in vitro silencing study was performed by using H-460 cells stably expressing firefly luciferase. Figure 5A showed the silence effect of anti luciferase siRNA in different formulations. Free siRNA does not have any silence effect because free siRNA can not penetrate the lipid membrane of cells. The naked or unmodified LCP NP showed a large silence effect but it also showed toxicity due to its cationic charges. PEGylated, but untargeted, LCP (LCP-PEG) showed a 20\% silencing effect, probably because the positive charge on LCP was sheltered to reduce the endocytosis. Compared to the untargeted PEGylated LPD formulation (LPD-PEG), the slight enhancement in silencing may be caused by the solid core of calcium phosphate. The AA targeted LCP (LCP-PEG-AA) had a significantly improved silencing effect 
compared to PEGylated but untargeted LCP (LCP-PEG) and down-regulated more than 60\% of the luciferase expression when the concentration of siRNA equaled to $100 \mathrm{nM}(\mathrm{n}=3)$. However, the targeted LPD (LPD-PEG-AA) only silenced $20 \%$ of the luciferase expression at the same concentration of the siRNA. If the control siRNA was entrapped in calcium phosphate and prepared as the LCP-PEG and LCP-PEG-AA formulations, there was no silence effect observed. The fact that LCP formulations always showed a stronger silencing effect than the corresponding LPD formulations can be seen in Figure 5B. The $\mathrm{IC}_{50}$, half maximal inhibitory concentration, of LCP was calculated to be $60 \mathrm{nM}$, which is three to four times lower than that of LPD (200 nM).

The cytotoxicity for LCP formulations were measured by MTT assay, which include the untreated group, luciferase siRNA in non-target LCP, luciferase siRNA in target LCP, control siRNA in target LCP and luciferase siRNA in the LPD formulation. The results were summarized as a supplemental figure 1. Similar to our previous formulation LPD, the in vitro experiments showed that there was no cytotoxicity for LCP with PEG coating or with PEG-AA coating. Compared to the untreated group, the survival values in all of these groups were from $98 \%$ to $103 \%$. There were no significant difference between the groups because the protection of PEG on the outer layer.

\subsection{In vivo luciferase gene silencing effect of LCP}

The in vivo luciferase gene silencing effect was demonstrated on a xenograft model by implanting H-460 cells to the nude mice. As shown in Figure 6, the PEGylated but untargeted LCP (LCP-PEG) showed a slight silencing effect to the expression of luciferase. However, the targeted LCP (LCP-PEG-AA) showed 50\% down-regulation effect, which was also similar to the corresponding LPD formulation. If the anti-luciferase siRNA was replaced by controlled siRNA, almost no silencing effect was observed in any formulation. This result demonstrated the siRNA delivery activity of LCP formulation in vivo.

The immunotoxicity study of the targeted LCP and LPD formulations was shown in figure 6 $\mathrm{B}$ as the result of C57BL/6 mice. The concentration of two important proinflammatory cytokines, IL6 and IL 12, in the serum was detected according to our previous study [6, 17]. It was shown that targeted LCP nanoparticle almost did not induce the production of IL 6 when the siRNA dose was up to $1.2 \mathrm{mg} / \mathrm{kg}$. For the IL 12, there was no increase at the dose of 0.6 $\mathrm{mg} / \mathrm{kg}$ with a slight increase at the dose of $1.2 \mathrm{mg} / \mathrm{kg}$. However, the LPD formulation caused a change at the dose of $0.6 \mathrm{mg} / \mathrm{kg}$ with a significant increase at the dose of $1.2 \mathrm{mg} / \mathrm{kg}$. Therefore, the LCP nanoparticle suggested a new approach to increase the delivery dose for in vivo siRNA therapy.

\section{Summary and Conclusion}

We have developed a novel LCP nanoparticle formulation with a new cargo release mechanism that is different from the well established proton sponge effect. The calcium phosphate in the core of LCP nanoparticles dissolved at low $\mathrm{pH}$ in the endosome, increased the osmotic pressure and caused endosome swelling and bursting to release the entrapped siRNA. The targeted LCP with a PEG coating showed an improvement gene silence effect in vitro. Compared to the LPD nanoparticles, the replacement of DNA/protamine complex by calcium phosphate also decreased the immunotoxicity to promise a potential application for clinical trial.

\section{Supplementary Material}

Refer to Web version on PubMed Central for supplementary material. 


\section{Acknowledgments}

The authors would like to thank Dr. Surendar Reddy Bathula for synthesizing the DSPE-PEG-anisamide. We thank the Michael Hooker Microscopy Facility at UNC for the microscopy images. The project was supported by National Cancer Institute (CA129835).

\section{References}

1. Chen Y, Sen J, Bathula SR, Yang Q, Fittipaldi R, Huang L. Novel Cationic Lipid That Delivers siRNA and Enhances Therapeutic Effect in Lung Cancer Cells. Mol Pharm. 2009

2. Li SD, Chen YC, Hackett MJ, Huang L. Tumor-targeted delivery of siRNA by self-assembled nanoparticles. Mol Ther 2008;16(1):163-169. [PubMed: 17923843]

3. Li SD, Huang L. Targeted delivery of antisense oligodeoxynucleotide and small interference RNA into lung cancer cells. Mol Pharm 2006;3(5):579-588. [PubMed: 17009857]

4. Li S, Huang L. In vivo gene transfer via intravenous administration of cationic lipid-protamine-DNA (LPD) complexes. Gene Ther 1997;4(9):891-900. [PubMed: 9349425]

5. Mukherjee A, Prasad TK, Rao NM, Banerjee R. Haloperidol-associated stealth liposomes: a potent carrier for delivering genes to human breast cancer cells. J Biol Chem 2005;280(16):15619-15627. [PubMed: 15695518]

6. Chono S, Li SD, Conwell CC, Huang L. An efficient and low immunostimulatory nanoparticle formulation for systemic siRNA delivery to the tumor. J Control Release 2008;131(1):64-69. [PubMed: 18674578]

7. Sokolova V, Epple M. Inorganic nanoparticles as carriers of nucleic acids into cells. Angew Chem Int Ed Engl 2008;47(8):1382-1395. [PubMed: 18098258]

8. Bisht S, Bhakta G, Mitra S, Maitra A. pDNA loaded calcium phosphate nanoparticles: highly efficient non-viral vector for gene delivery. Int J Pharm 2005;288(1):157-168. [PubMed: 15607268]

9. Olton D, Li J, Wilson ME, Rogers T, Close J, Huang L, Kumta PN, Sfeir C. Nanostructured calcium phosphates (NanoCaPs) for non-viral gene delivery: influence of the synthesis parameters on transfection efficiency. Biomaterials 2007;28(6):1267-1279. [PubMed: 17123600]

10. Maitra A. Calcium phosphate nanoparticles: second-generation nonviral vectors in gene therapy. Expert Rev Mol Diagn 2005;5(6):893-905. [PubMed: 16255631]

11. Roy I, Mitra S, Maitra A, Mozumdar S. Calcium phosphate nanoparticles as novel non-viral vectors for targeted gene delivery. Int J Pharm 2003;250(1):25-33. [PubMed: 12480270]

12. Eufinger H, Rasche C, Lehmbrock J, Wehmoller M, Weihe S, Schmitz I, Schiller C, Epple M. Performance of functionally graded implants of polylactides and calcium phosphate/calcium carbonate in an ovine model for computer assisted craniectomy and cranioplasty. Biomaterials 2007;28(3):475-485. [PubMed: 16996127]

13. Sokolova VV, Radtke I, Heumann R, Epple M. Effective transfection of cells with multi-shell calcium phosphate-DNA nanoparticles. Biomaterials 2006;27(16):3147-3153. [PubMed: 16469375]

14. Welzel T, Meyer-Zaika W, Epple M. Continuous preparation of functionalised calcium phosphate nanoparticles with adjustable crystallinity. Chem Commun (Camb) 2004;(10):1204-1205. [PubMed: 15136839]

15. Liu T, Tang A, Zhang G, Chen Y, Zhang J, Peng S, Cai Z. Calcium phosphate nanoparticles as a novel nonviral vector for efficient transfection of DNA in cancer gene therapy. Cancer Biother Radiopharm 2005;20(2):141-149. [PubMed: 15869447]

16. Banerjee R, Tyagi P, Li S, Huang L. Anisamide-targeted stealth liposomes: a potent carrier for targeting doxorubicin to human prostate cancer cells. Int J Cancer 2004;112(4):693-700. [PubMed: 15382053]

17. Li SD, Chono S, Huang L. Efficient gene silencing in metastatic tumor by siRNA formulated in surface-modified nanoparticles. J Control Release 2008;126(1):77-84. [PubMed: 18083264]

18. Hirst RA, Harrison C, Hirota K, Lambert DG. Measurement of [Ca2+]i in whole cell suspensions using fura-2. Methods Mol Biol 1999;114:31-39. [PubMed: 10081008]

19. Tseng YC, Mozumdar S, Huang L. Lipid-based systemic delivery of siRNA. Adv Drug Deliv Rev. 2009 
20. Thomas M, Klibanov AM. Enhancing polyethylenimine's delivery of plasmid DNA into mammalian cells. Proc Natl Acad Sci U S A 2002;99(23):14640-14645. [PubMed: 12403826]

21. Yang S, May S. Release of cationic polymer-DNA complexes from the endosome: A theoretical investigation of the proton sponge hypothesis. J Chem Phys 2008;129(18):185105. [PubMed: 19045433]

22. Hafez IM, Maurer N, Cullis PR. On the mechanism whereby cationic lipids promote intracellular delivery of polynucleic acids. Gene Ther 2001;8(15):1188-1196. [PubMed: 11509950]

23. Torchilin VP. Recent advances with liposomes as pharmaceutical carriers. Nat Rev Drug Discov 2005;4(2):145-160. [PubMed: 15688077]

24. Epple, MaS; V. Inorganic Nanoparticles as Carriers of Nucleic Acids into Cells. Angewandte Chemie International Edition 2008;47

25. Graham FL, van der Eb AJ. A new technique for the assay of infectivity of human adenovirus 5 DNA. Virology 1973;52(2):456-467. [PubMed: 4705382]

26. Li SD, Huang L. Nanoparticles evading the reticuloendothelial system: Role of the supported bilayer. Biochim Biophys Acta. 2009

27. Morgan TT, Muddana HS, Altinoglu EI, Rouse SM, Tabakovic A, Tabouillot T, Russin TJ, Shanmugavelandy SS, Butler PJ, Eklund PC, Yun JK, Kester M, Adair JH. Encapsulation of organic molecules in calcium phosphate nanocomposite particles for intracellular imaging and drug delivery. Nano Lett 2008;8(12):4108-4115. [PubMed: 19367837]

28. Wier WG, Beuckelmann DJ, Barcenas-Ruiz L. [Ca2+]i in single isolated cardiac cells: a review of recent results obtained with digital imaging microscopy and fura-2. Can J Physiol Pharmacol 1988;66 (9):1224-1231. [PubMed: 3064899] 


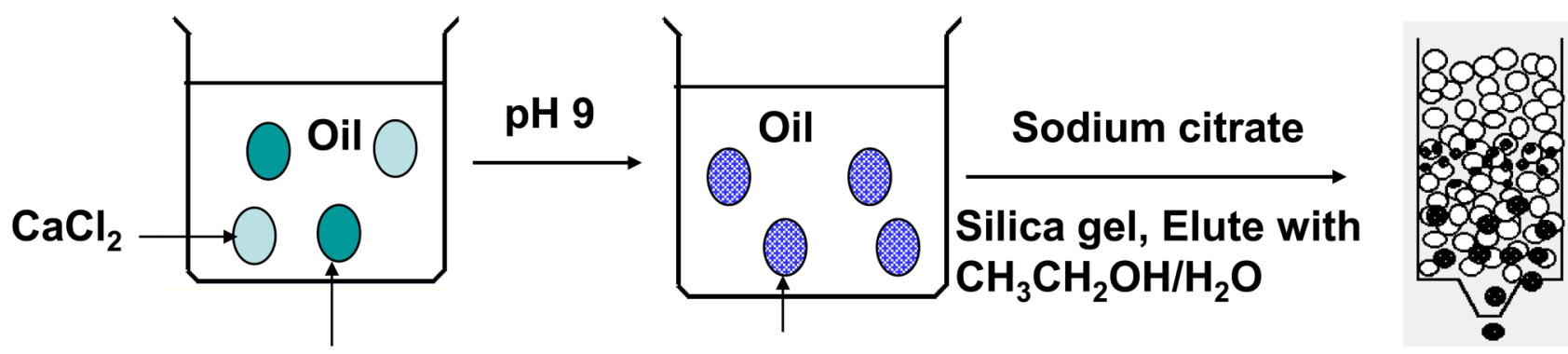
siRNA, $\mathrm{HPO}_{4}{ }^{2-} \quad$ NP with siRNA

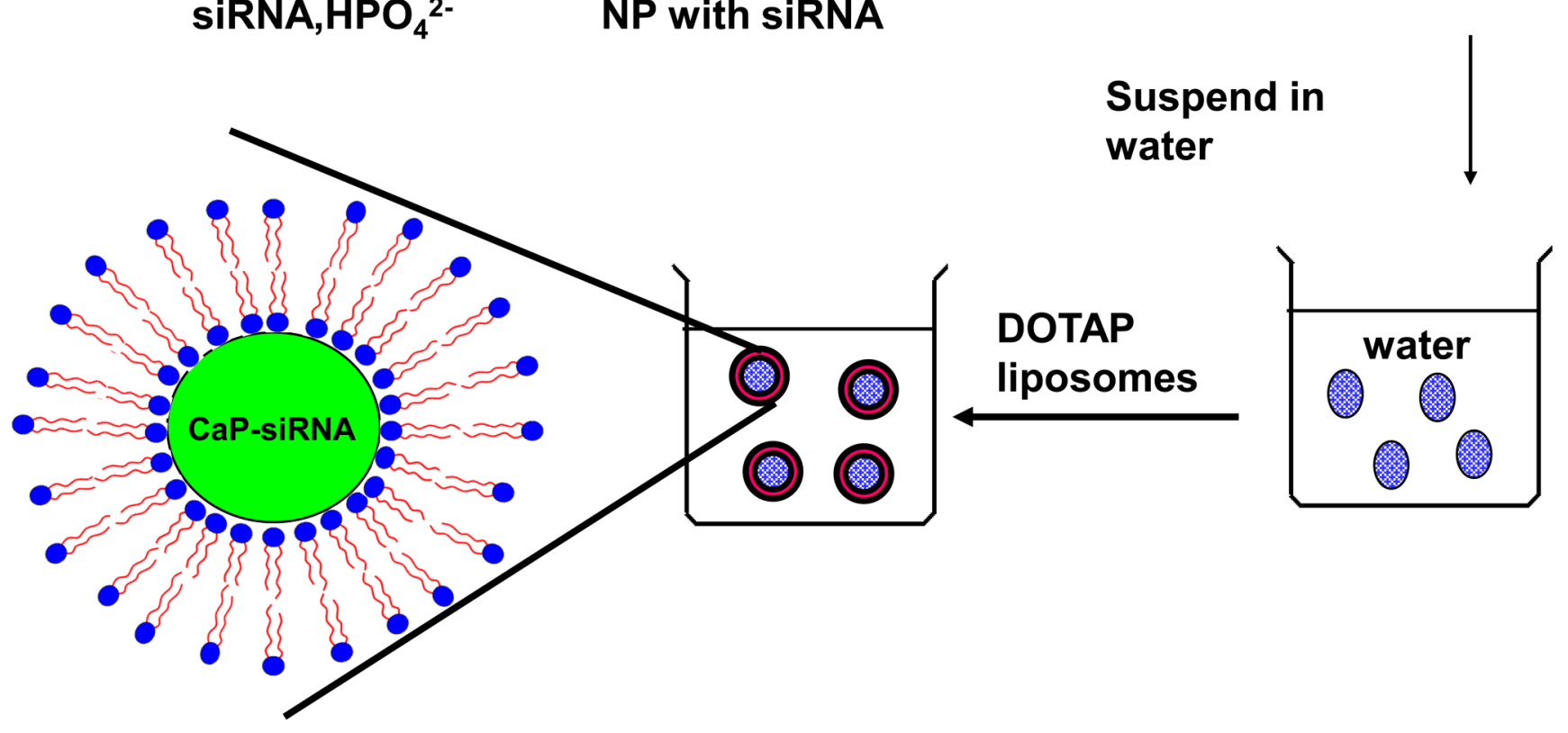

Figure 1.

The formation process of liposome/calcium/phosphate (LCP) nanoparticles. 


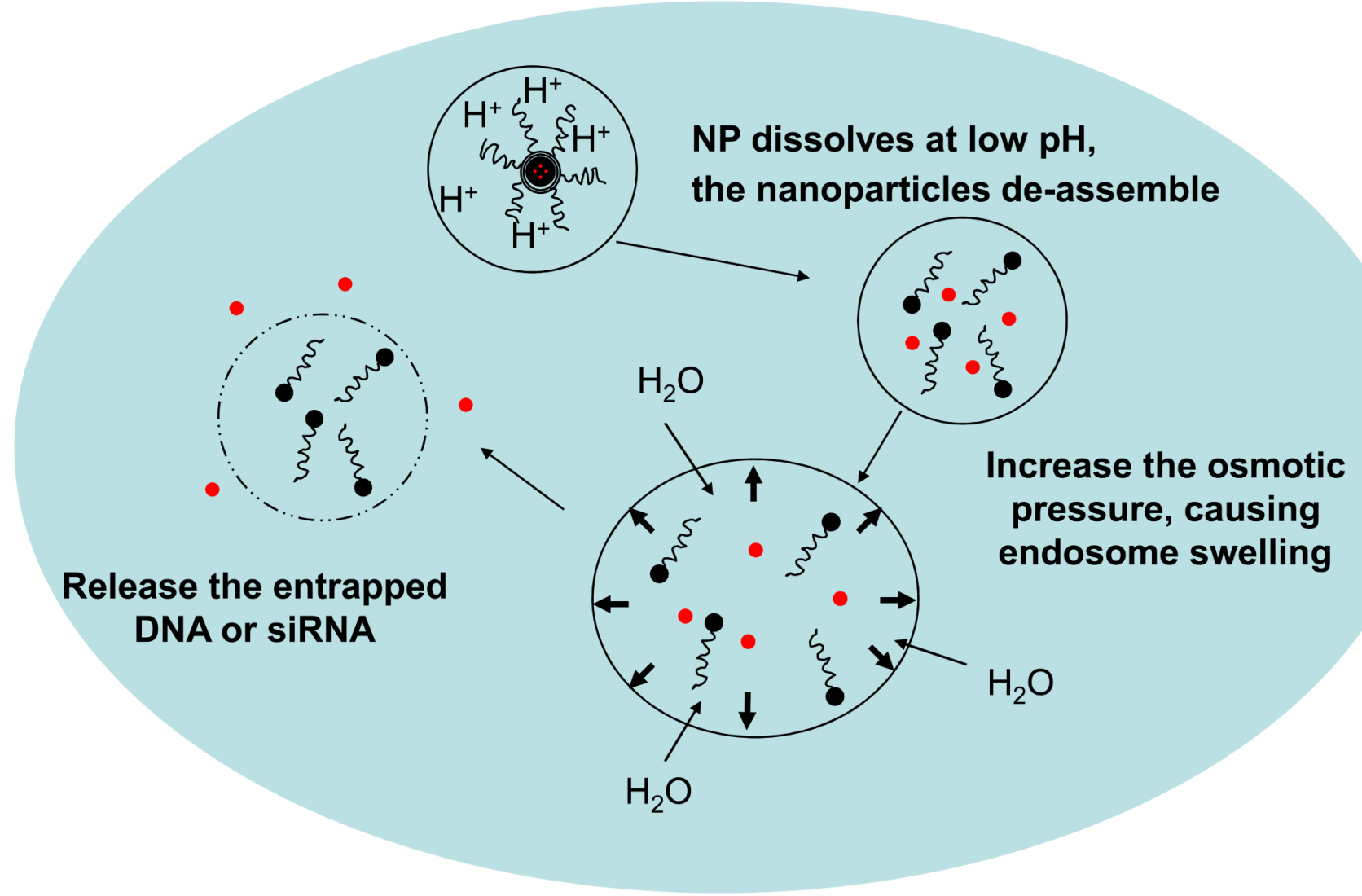

Figure 2.

The hypothesized release process of siRNA entrapped in LCP after endocytosis to the endosome. There are four steps for siRNA released from LCP. (1) The LCP enters the cell through endocytosis and stays in the endosome. (2) The CaP core is dissolved at low $\mathrm{pH}$, causing NP de-assembly. (3) The dissolved calcium and phosphate ions increase the osmotic pressure and cause endosome swelling. (4) The endosome bursts and releases the siRNA, calcium and phosphate ions into the cytoplasm. 

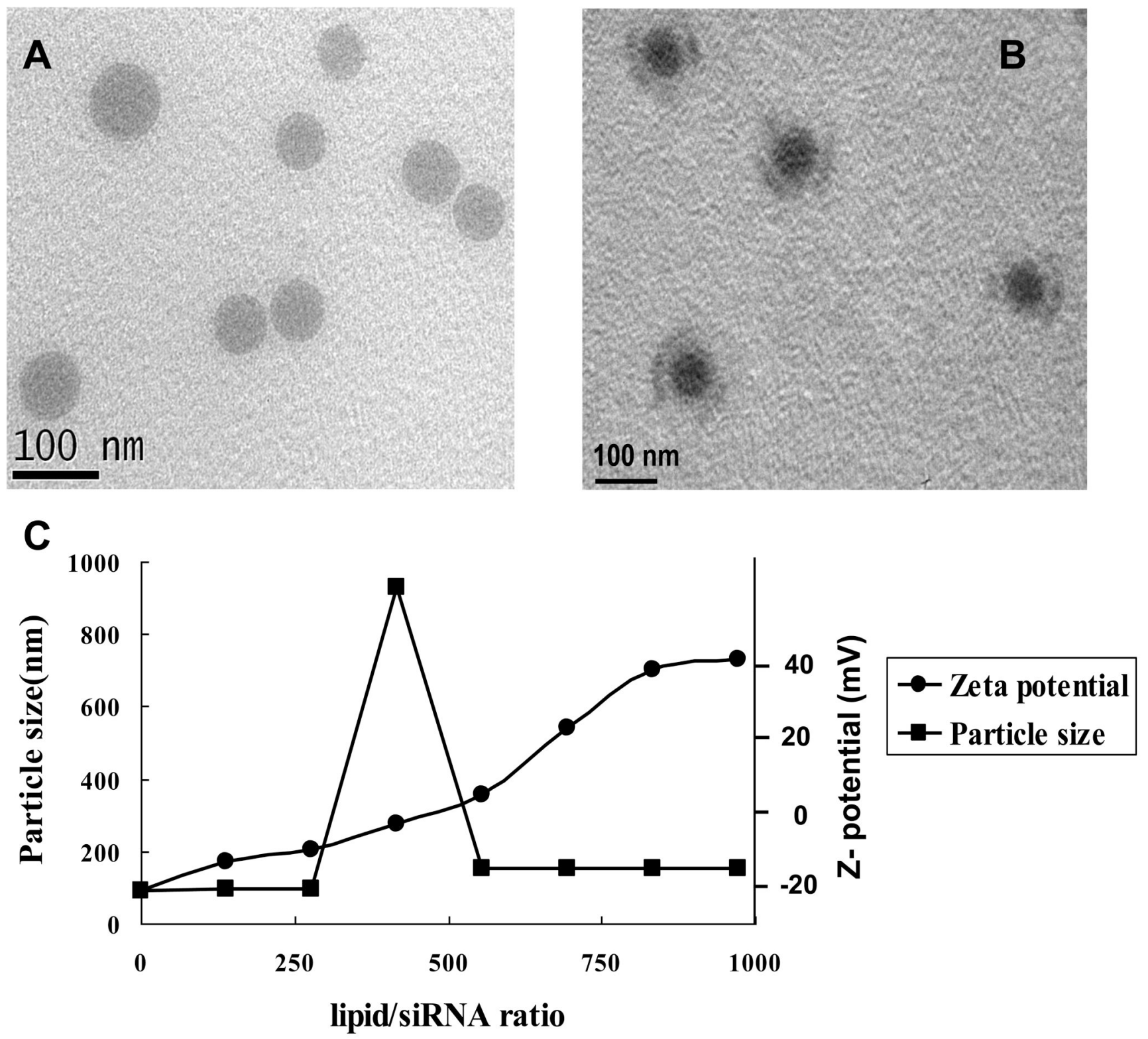

Figure 3.

The TEM imaging of (A) siRNA entrapped in calcium phosphate. (B) The LCP nanoparticle with negative staining. (C) Effect of lipid/siRNA molar ratio on particle size and zeta potential of LCP. 

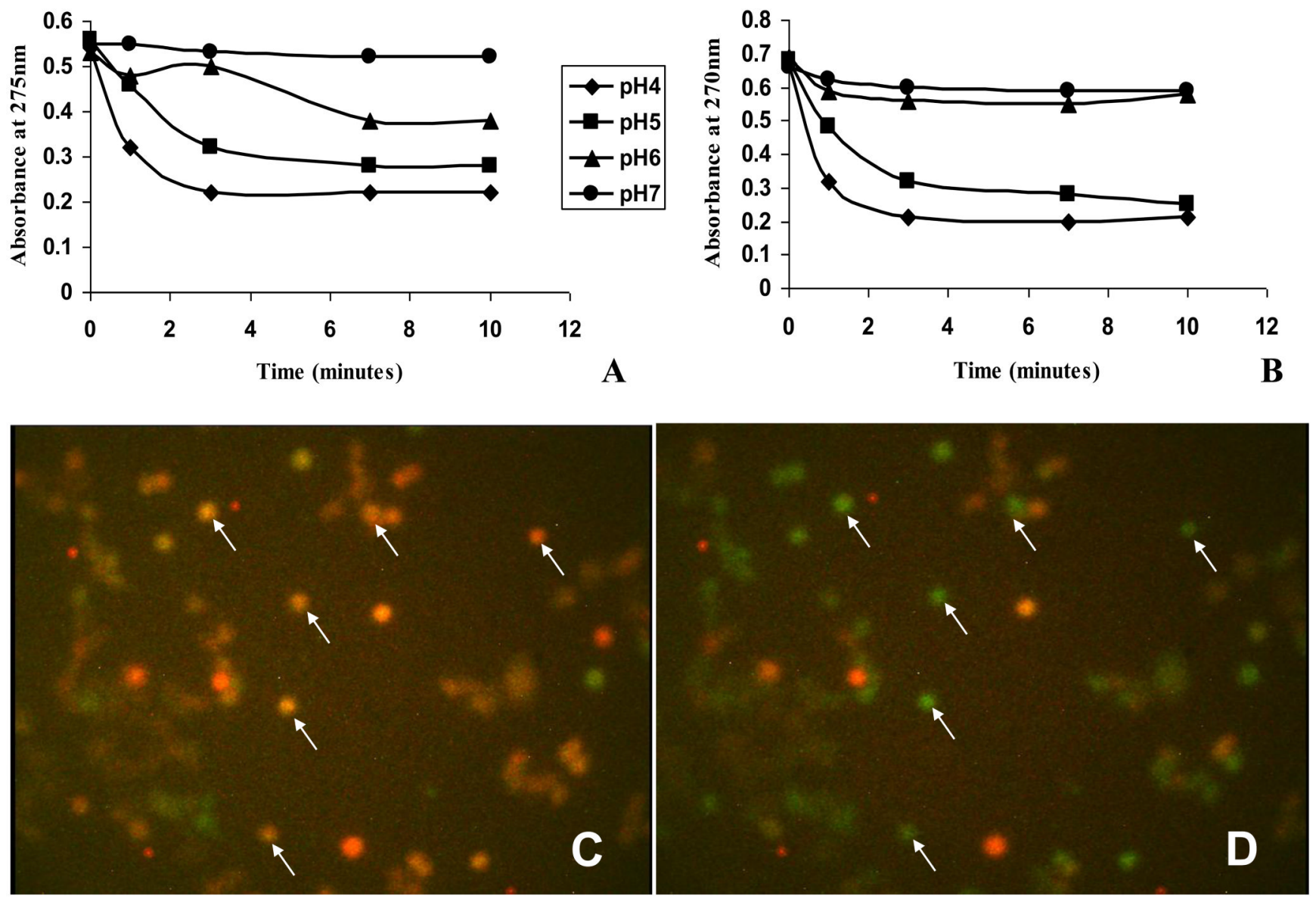

Figure 4.

The release profile of LCP. Light scattering of CaP/siRNA (A) and siRNA in LCP (B) at different $\mathrm{pH}$. The fluorescence images of Fura- 2 labeled H-460 cells before (C) and after (D) the addition of LCP. The arrows indicate cells that changed color from red $\left(\right.$ low $\left.\mathrm{Ca}^{2+}\right)$ to green $\left(\right.$ high $\mathrm{Ca}^{2+}$ ). 


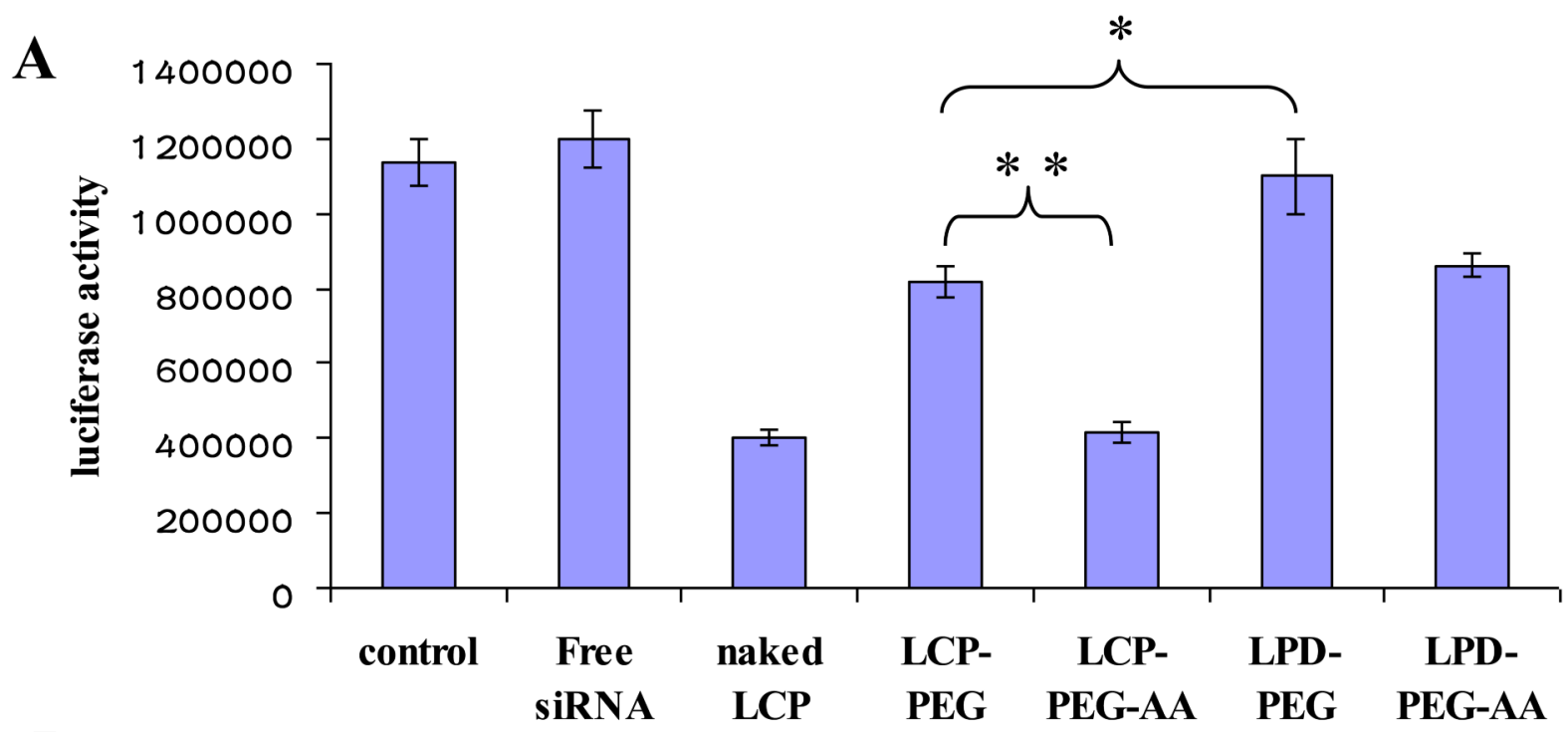

B

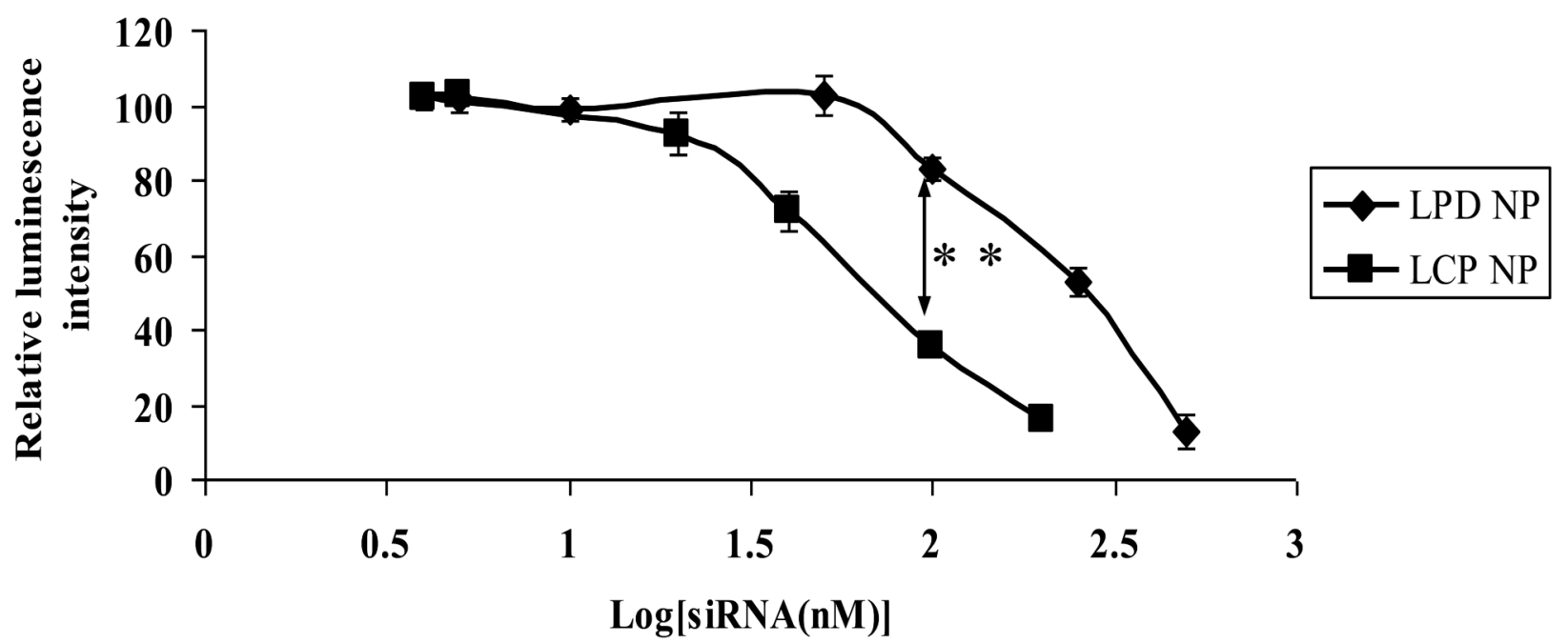

Figure 5.

(A) In vitro luciferase gene silencing effect of different formulations in $\mathrm{H}-460$ cells by incubation at $37^{\circ} \mathrm{C}$ for $24 \mathrm{~h}(\mathrm{n}=5)$. The amount of siRNA in LCP formulation was $99.8 \pm 6.9$ $\mathrm{nM}$ by evaluating the entrapped fluorescently labeled siRNA. For the LPD formulations, the concentration of FAM labeled siRNA was $100 \mathrm{nM}$. (B) The measurement of IC50, half maximal inhibitory concentration, of LCP-PEG-AA and LPD-PEG-AA. * indicates $\mathrm{p}<0.05$, $* *$ indicates $\mathrm{p}<0.01$. 


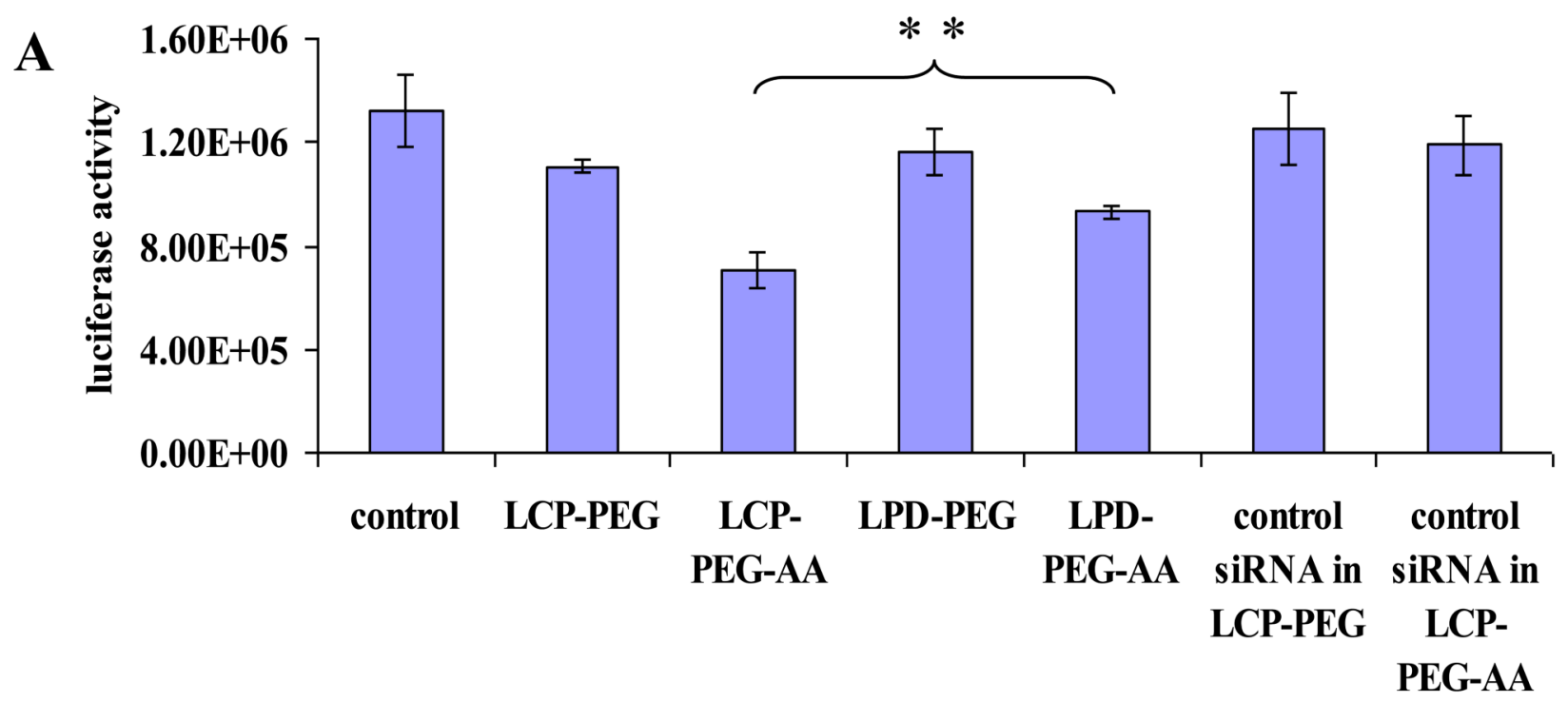

B

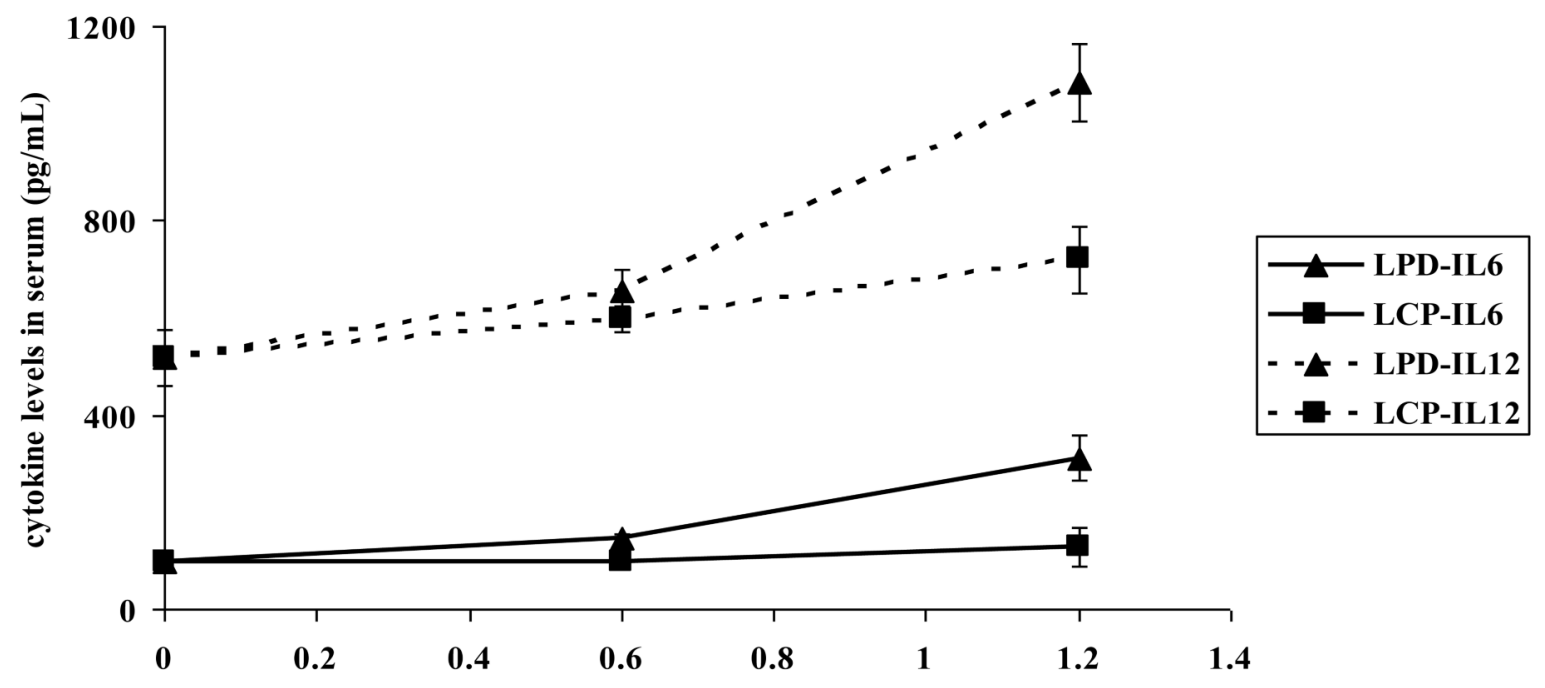

Injected siRNA dosage

Figure 6.

(A) In vivo luciferase gene silencing effects of different formulations at the dose of $1.2 \mathrm{mg} /$ $\mathrm{kg}$. The luciferase activity in H-460 cells was measured after 24 hours of the i.v. injection with different siRNA formulations. (B) The serum IL-6 (solid line) and IL-12 (dash line) levels of the mice after 4 hours of the i.v. injection with targeted LCP (squares) and LPD (circles) formulations at different dose of siRNA. ** indicates $\mathrm{p}<0.01$. 